\title{
Impact of Scouting Program in Punakha District, Bhutan on Youth Identity and Self-esteem
}

\author{
Kinzang Wangchuk ${ }^{1 *}$ and Sonam Tshering ${ }^{2}$ \\ ${ }^{1}$ Laptsakha Primary School, Department of School Education, Bhutan \\ ${ }^{2}$ Nawakha Primary School, Department of School Education, Bhutan \\ *Corresponding Author: Kinzang Wangchuk, Laptsakha Primary School, Department \\ of School Education, Bhutan.
}

Received: May 11, 2021

Published: June 23, 2021

(C) All rights are reserved by Kinzang

Wangchuk and Sonam Tshering.

\section{Abstract}

Scouting program in considered globally as one of the youth development program to enhance young people in developing lifelong skills such as leadership qualities, decision making, and character building [11,14]. Scouting program provides good learning experiences and skills for young people to help in recognizing and identifying the values and goals in life and how to confront the pertaining issues in today's contemporary world like drug abuse, teenage pregnancy, sexual abuse/harassment and create better communities [12,16]. The program inspires and motivates youth to be more responsible, keeping them engaged in useful activities and empowering them to be responsible and productive citizens. The success of the scouting program depends immensely on the parent's encouragement and support for their children to participate in the scouting movement, the participation in activities and communication between parents, leaders and peers broaden their skills on leadership, self-identity, self-esteem, personal values, decision making, courage, and character building $[13,16]$. This research project recognizes the scouting program and its impact on youth identity and self-esteem. It is a youth development program that mould the young minds and is an effective initiative for grooming the future leaders in Bhutan. This study found that scouting program is an effective and efficient initiative for overall youth development program and capacity building of future leaders in the country. The survey also reveals that some schools do not have any monitoring system to see whether the teachers are carrying out their roles and responsibilities seriously. The research also recognized that scouting program has not been able to make significant inspiration and motivation into the minds of young people, parents and stakeholders alike. This means, the benefits and impact of scouting program are not earned by many youths - a missed opportunity for the nation. Further, the research project identifies that the success of scouting to an extent depends on a strong partnership between the various stakeholders within the country. The key is identification and understanding of Scouting as a common goal by all the stakeholders inclusive of teachers, parents and Ministry of Education (MoE). By doing so, there will be less resistance and more proactive participation from the teachers enhancing the quality of Scouting programs that will directly result in the student academic achievements. The study also suggests Department of Youth and Sports, in particular Scouts and Cultural Education Department to plan the scouting programme referring the school yearly plan and conduct mass advocacy program. Infuse scouting programme in the school curriculum and improve its support service to the schools in carrying out scouting effectively with good monitoring mechanism in place. And finally, the success of scouting also depends on the personal motivation and energy level of the scout leaders. Moreover, there is no such research carried out on scouting, in the past, the success and failure of scouting program is little known and recorded. Due to the lack of availability of resources, time constraint, and budget this study may not be able to make a comparative understanding of the scouting in different schools.

Keywords: Scouting; Youth Identity; Self-esteem; Capacity-building; Leadership 


\section{Introduction}

Scouting offers unique opportunities for scouts in taking up lifelong learning in the field of leadership skills focusing on, values and ethics, obedience, loyalty, trust, helpfulness, brotherhood, cleanliness and life skills. As per Lord Baden Powell [15], "We have always been fond of saying that Scouting is a game with a purpose. Scouting is about three things, it is all about fun, values, and most importantly learning. Fun is the game, learning is the process, and values are the purpose." Scouting is also a process to develop character within individual children through practical experiences [6]. Scouts will have a sense of self-development through multiple activities in scouting program in regard to physical, mental and emotional developments; they can also use their best abilities and contribute as good citizens and build a happy nation [7]. As emphasized by World Organization of the Scout Movement (WOSM) describes scouting as "a voluntary non-political educational movement for young people open to all without distinction of origin, race or creed, in accordance with the purpose, principles and method conceived by the founder" [17]. Scouting is an education for life and comprises of school and the family by developing self - knowledge, the need to explore, to discover, to want to know and learn visual skills, to be trained in the code of living and leadership, based on a system of values such as honesty $[2,4]$.

The scouting movement was founded by Lord Baden Powell in 1907 in England and based on the ideas of the founder, the scouting program has proved as a universal appeal for scouts which spread worldwide in the globe and created a strong brotherhood among the scouts with high a sense of responsibilities and loyalty $[5,9,10]$. The promotion of unity and teamwork further flourish among the youth creating a platform to exhibit their talents and encourage those shy ones to take up a lead. Bhutan Scout Association states that the focus of the program was to school children and some scouting programs had been conducted [1]. However, it could not take its root, since they could not make the scouting popular among the youth and that strong support could not be mobilized [1]. The scouting guiding principles, law and motto having found useful and potential for youth through scouting program in allround development of a child. Bhutan Scouts Association (BSA) was established in the year 1996. Consequently, on 26th July 1999, Bhutan Scouts Association (BSA) became a full-fledged member of the World Organization of the Scout Movement (WOSM). With the growing interest and deriving positive impact from the scouting program, Bhutan Scout Association have strengthened the continuity of scouting programme to pursue it as a lifelong education, the Community Based Scouting was introduced in Thimphu in 2009. The Community Based Scouting provides voluntary service to the community, institutions as well as to individuals in a wider range [1]. The main aim of this research project was to assess and find out the impact of scouting program in Punakha district, on youth identity and self-esteem. The study also aims at finding out the effectiveness of the program and activities carried out and justify the evolution of youth identity and self-esteem between the Scouts (treatment group) and non-scouts. It highlights some other factors and measures for scouting program in future.

In a research project, the research problem should be very clear to overcome the issues and suggest the appropriate forms for its investigation. It is a declaration about a particular matter of any pertaining issue that needs to be addressed with good hypotheses and how they can be formulated. Research problem denotes to some difficulty where a researcher experiences in the context of either a theoretical or practical situation and wants to obtain a solution [8]. With the integration of scouting program since the 1980s in the country, no studies have been carried out to find out the impact of scouting program on students. Though many youth beneficial activities, precisely for scouts are being carried out in the district for their overall development but there is no such concrete follow-up or impact study done till date. Therefore, the study would be of immense help for the District, Department/Organization and Education Ministry for the way forward in implementing and strengthening the scouting program.

In a research project, the purpose of research study specifies in finding the answers to questions through the application of systematic actions and aims in generating the truth which is hidden and which has not yet discovered [8]. The study will strengthen to identify those scouters those who have achieved a high profile in their life and developed their self-esteem and self-identity through scouting program. Further, the study will also help the policy makers to frame the policies, revisit the existing policies and further enhance the scouting activities in the country and provide necessary support in promoting the movement. 
The main objectives of the study are to find out the impact of scouting activities and overall youth identity, self-esteem, motivating factor to be a scout and measures for way the forward in future to promote and strengthen scouting movement in Bhutan. The following are the key objectives of the study:

- To compare the overall performance of scout (treatment group) and non-scout (controlled group) students at different stages of scouting programme in the District.

- To find out the challenges in the implementation of scouting program in schools and district.

- $\quad$ To find out what are the motivating factors to be a scout.

\section{Research question}

- How effective and active is scouting program in the district?

- Is there an evolution in youth identity and self-esteem between the Scouts (treatment group) and non-scouts (controlled group)?

- How effective are the programs carried out helpful for the scouts in the district?

- What are the way forwards for carrying out scouting program in the district?

\section{Materials and Methods}

Research methodology is an approach used and applied systematically to solve the research problem and recognize the assumptions of underlying various methods [8]. For this research project, we have focused on a deductive approach to finding out what are the influencing factors being in scout and how children's self-identity and self-esteem is being developed. Based on this hypothesis, we have framed questionnaire for scouts and scout leaders as attached in appendix I and II.

\section{Study area}

The proposed study was carried out in Punakha Dzongkhag. The data was collected from two types of respondents viz. 1. Scout leaders, and 2. Scouts. Punakha Dzongkhag Scout Association has 1309 scouts, (Boys -746 and Girls -563). Currently Dzongkhag has 27 Schools. Out of 27 schools, for the research project, we have carried out my research questionnaire in 15 schools and 15 scout leaders, 25 Boys and 25 Girls (Scouts) as respondents. The fifteen schools that we have selected are Punakha HSS, Kabesa MSS, Logodama PS, Khuruthang MSS, Nobgang PS, Laptsakha PS, Dechentshemo MSS, Dashiding HSS, Lobesa LSS, Tsochasa PS, Mendelgang PS, Shengana LSS, Tashidingkha MSS, Jibjokha LSS, and Nawakha PS. The reason for selecting the District is mainly to cut down the cost expenses and complete the task on time.

\section{Research design}

A research design is the plan of conditions for data collection, measurement and analysis which aims to combine relevance to the research purpose with economy in procedure [8]. This research was carried out using the quantitative method. The logic behind the quantitative method is because of the nature of research being academic research the framed objective won't get diverted. Mover over the data collection is convenient to generate and the findings through using numbers, tables, graphs and figures. Further, it is also easy to correlate between the independent and dependent variable to find out the effects and causes within given theoretical framework.

\section{Sampling technique}

The reason for the simple random sampling is to get fair data because every member gets the equal opportunity; moreover, it represents the population of the research conducted. It will also help in indiscriminately selecting respondents, which will provide fair and just responses to the survey. The survey was carried out in person and all the respondents were identified in consultation with the scout leaders and principal of the school. The questionnaire was distributed to the respondents and collected back on completing the task for further compilation.

\section{Issues of reliability and validity}

In our research project in order to have reliable and validate survey questionnaires, we have focused on strategies like triangulation, peer examination, pretesting and submersion to ensure the validity. And also relied on the dependability and consistency with the data generated. The survey questionnaires were provided to 5 scouts and 5 scout leaders for pretest the question, and after the conduct of pretest I have collected feedback and improved on the same. 


\section{Data sources}

\section{Primary data collection}

The primary data was collected from the randomly selected schools in the District through questionnaires for the quantitative analysis. The interviews consisted of four demographic questions for both scouts and scout leaders (1) Level of school (PS, LS, MSS, HSS (2) Sex-M/F (3) No. of experience -Years/Months as a School Commissioner/Scout Leader (4) Dzongkhag/Thromde. The questionnaires for scout leaders consist of 13 questions (Likert scale) and 3 open-ended questions, totaling to 16 questions. And for scouts the questionnaires consists of 15 questions (Likert scale) and 3 open-ended questions, totaling to 18 questions.

\section{Secondary data collection}

Secondary information required will be collected from the books, review of relevant articles and journals, plan documents, policy and acts documents, and national reports related to this study. For authentication, the academic transcript for scouts is also used as secondary data. Since the study is focused on Punakha district and all the related documents for secondary data will be collected from District Education office, District scout focal person and schools.

\section{Data collection techniques}

The findings from this research will extrapolate to the scouting program in the country and it is expected to use as a data source. For this study, with consultation from District Scout Focal and Scout Masters, We have carried out focused group interview for the selected respondents for scouts and leaders. The selected respondents were provided with the set of questionnaires to answer and given the opportunity to ask clarifications if necessary.

\section{Data analysis and interpretation}

For data analysis and interpretation, we have recorded all the data in hard copy during the survey and complied separately. After compilation of survey questionnaires, we have punched data in Statistical Package for Social Science (SPSS) using different codes for demographic questionnaires and Likert scale. For the analysis of data, the statistics generated from SPSS such as graphs, tables and charts are used. The central tendencies like mean, median, mode and standard deviation were looked at for the data analysis and interpretation. 8. Procedure/Measures The questionnaire is made of 28 structured questions and 6 open-ended questions (13 structured questions and 3 open-ended questions for scout leaders and 15 structured questions and 3 open ended questions for scouts) items to rate the extent of existence for all variables in the research area on a five-point (Likert) scale ranging from strongly disagree to strongly agree: 1 - Strongly Disagree 2 -Disagree, 3-Neutral, 4-Agree, 5- Strongly Agree.

\section{Ethical consideration}

In academic writing, the most important aspect is to take care of ethical consideration, for the reliable and valid research the researcher need to consider the confidentiality and anonymity of the respondents in times of research survey. Before our survey, we have requested all respondents to fill up the consent form in order to maintain anonymity and their willingness for the participation as attached in appendix III. For the data collections in schools, we have approach Royal Institute of Management for consent letter and then from Department of School Education and Department of youth and Sports, Ministry of Education, District administration, Punakha and finally from the school principals.

\section{Results and Discussion}

For our research project, we have focused on four levels of schools, of which $40 \%$ respondents are from primary level schools and rest $20 \%$ are from LSS, MSS, and HSS respectively. There were 65 respondents in total, out of which 50 were scouts and 15 were scout leaders. To ensure the reliability and authenticity, $50 \%$ of the scout respondents were male and $50 \%$ female. Regarding the scout leaders, $53 \%$ were male and $47 \%$ female. $50 \%$ of the respondents both scouts and scout leaders have scouting experiences between 1 - 5 years, 30\% above $6-10$ years and 20\% have 11 years and above scouting experiences.

The survey indicates that $56 \%$ of scouts and $53 \%$ of scout leaders respondent believe in the development of self-identity and self-esteem through scouting program. From this study, it can be concluded that scouting movement has a positive impact in overall youth development, their identity and self-esteem. The survey also shows that $100 \%$ scouts believe that the program is youth development program while $98 \%$ scout leaders too feels that it is a youth development program. And rest $2 \%$ mentions that it is an extra work for them. 
The study proves that scouting movement builds their confidence, motivation and their preparedness for life situation. The study shows that $58 \%$ scouts strongly agree and also reveals that scouting has made them more competent and capable student in their life. In line, 53\% scout leaders strongly feels that scouts can educate and inspire others comparing to non-scouts. And also 46\% scouts leaders mentions that scouts are resourceful and helpful to others than non-scouts.

Scouting movement has a strong impact on youth identity and self-esteem, as both the respondents has revealed that $70 \%$ of scouts and 53\% scout leaders strongly agree that scouting develops and strengthen the leadership skills comparing to non-scouts. Scouts learn to lead the team and takes up opportunity and initiatives to exhibit leadership qualities in a group, team or troop. From the survey, it can conclude that scouting program has lots of benefits in terms of personal development like socialization, leadership skills, confidence, decision making. In addition, 80\% respondents stated that scouting helped in understanding and preserving rich culture and heritage.

The study also showed that with the inclusion of scouting programs in the schools, many youths were found engaged and active in all activities. About $47 \%$ of respondents believe that the academic performance of scout is better than better than the non-scouts. The study concludes that scouts are proactive all the time and most of the academic toppers are scouts.

The main challenges of the scouting movement are time constraint and limited support from Department of Youth and Sports (DYS), District Scout Association (DSA) and relevant stakeholders. Owing to these challenges scouting movement are inactive and there is less progression of the movement. Moreover, it is one of the factors that demotivates youths in actively participating in the scouting movement. The study shows that $73 \%$ of scouts feels that the biggest obstacle in the movement is time constraint and $26 \%$ is less support from DYS, DSA and concerned stakeholders. From the survey, it can be concluded that the biggest challenge for the scouts and scout leaders were limited time, the absence of support from the parents and agencies concerned.

\section{Conclusion}

While Scouting is regarded very important in educating and preparing the young minds into beautiful adults, the respondents felt they receive less support from the Department of Youth and Sports, Parents and District Scout Association which demotivated the scouts and scout leaders in the schools. Further, the time constraints in implementing the programme had hampered the efficiency of the programme. Despite the efforts made by the schools, scouting is not perceived to be functioning successfully in the schools. Therefore, it calls for a major intervention and support from the concerned agencies both at the District and Ministry. This research project recognized the scouting program has developed strong impact on youth identity and self-esteem. It is also one of the major youth development programs that mould the young minds and it is an effective initiative for grooming the future leaders in Bhutan.

The success of scouting program to a great extent depends on a strong partnership between the various stakeholders within the country. The key is identification and understanding of Scouting as a common goal by all the stakeholders inclusive of teachers, parents, youths and Ministry of Education (MoE). By doing so, there will be less resistance and more proactive participation from the teachers enhancing the quality of Scouting programs that will directly result in the student academic achievements. The study also suggests Department of Youth and Sports, in particular Scouts and Cultural Education Department;

- To plan the scouting programme referring the school yearly plan.

- Mass advocacy program of scouting program and its impact on youth.

- Develop scouting activities that can be practised in the limited time the schools can offer.

- Infuse scouting programme in school curriculum and improve its support service to the schools in carrying out scouting effectively.

- To develop evaluation and monitoring mechanism so as to improve the programme and make scouting a successful venture.

- The MoE experts need to study on how to formalize this kind of informal learning to add on to the scouting requirement. A feedback system on one seeking professional assistance from one another is needed. 
- $\quad$ The success of scouting also depends on the personal motivation and energy level of the scout leaders.

- Institute a bottom-up process of planning and implementation of scouting through the involvement of professional position holders.

The limitation seen in this study is that, since the study is done in one District, the result generated may not be enough to generalize for all. Moreover, it could be reliable if research is done in few more districts with more respondents and additional independent variables. To ensure the reliability and validity of data it would be good to have involved as many scout leaders, scouts and relevant stakeholders too. A study of scouting in remote schools would help in understanding the impact of the scouting on students in various level of schools in remote part of the country. Scouting in general is popular only in urban schools, thus the function of scouting remains bias depriving students in remote schools. Since, there is no such research carried out on scouting, in the past, the success and failure of scouting program is little known and recorded. Due to the lack of availability of resources, this study may not be able to make a comparative understanding of the scouting in different schools.

\section{Acknowledgments}

For the successful compilation of our research project firstly, we would like to express our deepest and sincere gratitude to our Professor Dr. Dennis Foley (Professor for Entrepreneurship, Management for Faculty of Business Government and Law), for the continuous support, guidance, patience, motivation and immense knowledge and insight for our research study. His guidance helped us in all the time of research and writing of this project. we could not have imagined having a better advisor, mentor and guide for my research project. Besides my advisor, we would like to thank Dr. Sonam Choiden (Professor, Royal Institute of Management) for taking me through basic requirements in research methods which were indeed an eye opener for us.

Besides, we would also like to thank the professionals who were involved in the validation survey and encouragement for this research project: Mr. Karma Tenzin (Chief Program Officer, Department of Youth and Sports, Scouts and Cultural Educational Division), Mr. Thinley Dorji (Education Monitoring Officer), Mrs. Dechen Wangmo (Lecture/Sr. Councilor, Centre for Contemplative Counselling Education and Research, Samtse College of Education),
Mr. Dawa Drakpa ( Currently Undergoing Master program in Education Management, Mahidol University, Thailand) and Mr. Chrysolyte Choragudi (Undergoing Masters in Business Management in RIM), Mr. Tashi Wangchuk (Sr. Program Officer, Department of Youth and Sports), Mr. Karma Wangdi (Research officer, Center for Bhutan Studies), and my MBM/MBA (2016-2017) friends. Without their passionate participation and input, the validation survey could not have been successfully conducted. Our sincere thanks also go to Director General, Department of Youth and Sports, Department of School Education and Royal Institute of Management, District Education Officer, Principals, scout Masters and Scouts under Punakha District for the necessary support rendered during our data collection from the schools. Without they precious support it would not be possible to conduct this research and complete on time. Finally, our heartfelt gratitude to my wife for her moral support all the time and continuous encouragement during my entire course.

\section{Conflict of Interest}

None.

\section{Bibliography}

1. Bhutan Scout Association. Scouting in Bhutan (2009-2010).

2. Boy Scouts of America. "Benefits" (2016).

3. Boys Scout of America. "International” (2016).

4. Boys Scouts of America. "Boys scouts of America” (2016).

5. Boys Scouts of America. "The world organization of the scout movement" (2016).

6. Gowan D. "The Scouting pages - Famous scouts".

7. Harris L and Associates. "A year in a life of a Cub Scout, Boy Scout, venture". New York: Boy Scouts of America (1998).

8. Kotheri C R. "Research Methodology methods and technology". New Delhi: New Age International (P) Ltd., Publishers (2004).

9. Peace and Corporate Economic Consultants. "A study of the impact of scouting on the UKs Young people, adults and communities". England and Wales: The Scout Association Registered Charity (2011).

10. Poole E L. “Life's Lessons of Scouting, Leadership, and Mentorship". Peri Anesthesia Nursing 3 (2014). 
11. Scouts Australia. "Scout Australia: About Scouts - Famous scouts" (2016).

12. Scouts Australia. "Scouts Australia - Famous Scouts" (1998).

13. Scouts Australia. "About scouts/Famous Scouts" (2016).

14. Tufts University (2014).

15. Wangchuk T and Wangdi L. "Scouting for Scouts. Samtse: College of Education, Samtse" (2007).

16. Wendy Peay. "Scouting Teaches Values, Importance of Community Service" (2016).

17. World Scout Bureau. "Constitution of the world organization of the scout movement". World Scout Bureau 19 (2011).

Volume 4 Issue 7 July 2021

(c) All rights are reserved by Kinzang Wangchuk and

Sonam Tshering. 